\title{
Mitos e Realidades sobre a Difusão do Comércio Eletrônico nas Empresas Brasileiras*
}

\author{
Paulo Bastos Tigre \\ Instituto de Economia, Universidade Federal do Rio de Janeiro \\ Jason Dedrick \\ University of California, Irvine
}

Recebido em 9/4/2003 Aprovado em 3/6/2003

\section{RESUMO}

A difusão das tecnologias da informação, e mais recentemente da Internet vem gerando expectativas de transformações radicais na forma de funcionamento da economia mundial. Três hipóteses particularmente importantes pela sua abrangência são destacadas na literatura especializada e serão discutidas neste artigo com base em pesquisas empíricas sobre a difusão do comércio eletrônico conduzidas pelo projeto Globalization and Electronic Commerce, coordenado pela Universidade da Califórnia, Irvine. A primeira é que o processo de difusão do comércio eletrônico está bidirecionalmente associado ao processo de globalização. A segunda é que haveria uma "nova economia" baseada nas novas empresas intensivas em informação. A terceira hipótese analisada é que o comércio eletrônico reduz as desvantagens estruturais das micro e pequenas empresas, graças a seus impactos informacionais e espaciais. Com base em entrevistas com 200 empresas, a pesquisa revela que, pelo menos no caso do Brasil, tais hipóteses não estão se confirmando e que apesar da

\footnotetext{
"Este artigo integra o projeto Globalization and E-Commerce do Center for Research on Information Technology and Organizations (CRITO) da Universidade da California em Irvine. A pesquisa tem apoio financeiro da National Science Foundation (CISE/IIS/CSS) nos Estados Unidos e do CNPq no Brasil. Agradecemos os comentários e sugestões de Ken Kraemer, Liz-Rejane Issberner, Renata La Rovere e dos pareceristas anônimos que se dispuseram a comentar os originais.
} 
inegável importância do comércio eletrônico, a tecnologia não determina a estrutura da indústria nem modifica estratégias de globalização. Por outro lado, o artigo confirma que comércio eletrônico é uma importante ferramenta para ajudar empresas e países a desenvolverem trajetórias econômicas preexistentes.

Palavras-Chave | Comércio Eletrônico; Globalização; Nova Economia; Competitividade; Tecnologias da Informação; Difusão de Tecnologia; Micro e Pequenas Empresas

Códigos JEL | B5, M2, L1, L2, D84

\section{ABSTRACT}

The rapid diffusion of information technologies and the Internet gave birth to radical interpretations about their worldwide economic impacts. Three hypotheses widely discussed in the specialized literature are particularly interesting for their relevance for economic analysis and will be reviewed in this article based on empirical research on electronic commerce (EC) conducted by the Globalization and Electronic Commerce project at the University of California, Irvine. The first hypothesis states that EC diffusion is both a driving force and a consequence of the globalization process. The second is that new IT is giving birth to a "new economy" based on new information-based firms. Finally we analyze the hypothesis that EC is reducing the competitive disadvantages of small firms face their larger counterparts, thanks to informational and geographical impacts. Based on a survey with 200 firms, the article concludes that, at least in the case of Brazil, the findings do not support those hypotheses and that despite the undisputed importance of EC for business development, the technology itself determines neither industry structure or firms globalization strategies. Rather, EC helps firms and countries to further explore their existing economic trajectories.

KeYwords | Electronic Commerce; Globalization; New Economy; Competitiveness; Information Technologies; Technology Diffusion; Small Firms

JEL-Codes $\quad$ B5, M2, L1, L2, D84 


\section{Introdução}

Desde que o uso comercial da Internet foi autorizado nos Estados Unidos em 1995, o comércio eletrônico tem sido apontado como uma inovação radical, capaz de revolucionar mercados e organizações. A explosão da demanda por acesso digital em banda larga (DSL, ADSL e CATV) ${ }^{1}$ e redes sem fio de alta velocidade mostram que, apesar do estouro da bolha da Nasdaq, os negócios virtuais continuam em rápida ascensão. Pouco se sabe, entretanto, sobre o processo de difusão da nova tecnologia, de seus determinantes e impactos. A literatura especializada tende a focalizar casos de empresas líderes que não podem ser generalizados pelo fato de refletirem situações específicas. Cada país, setor ou empresa se defronta com diferentes oportunidades e obstáculos para adotar novas tecnologias e práticas de negócios eletrônicos. O ritmo e a direção da difusão são diretamente influenciados pelo ambiente econômico, pelo papel do país na economia global, pelas políticas públicas adotadas e pelas experiências prévias na adoção de tecnologias afins. São também condicionados pelas características das empresas e indivíduos que implementam e usam a tecnologia. Tais fatores acabam por influenciar os impactos da nova tecnologia ao nível empresarial e nacional.

Este artigo, elaborado com base na pesquisa Globalization and Electronic Commerce, envolvendo dez países em três continentes, ${ }^{2}$ analisa os fatores condicionantes da difusão do comércio eletrônico e seus impactos nas empresas. Em cada país foram realizadas entrevistas com 200 estabelecimentos nos setores financeiro, industrial e comercial, ponderados segundo o porte. ${ }^{3}$ Cabe esclarecer que alguns conceitos foram simplificados de forma a facilitar o entendimento. Ao longo do texto usamos freqüentemente o adjetivo global para se referir ao conjunto de dez países, o que rigorosamente não corresponde à realidade. Comércio eletrônico é tratado de forma ampla, incluindo Internet e outras formas de transmissão de dados como o electronic data interchange (EDI). Também são consideradas como comércio eletrônico operações interativas que não necessariamente envolvem o fechamento de negócios, a exemplo do suporte técnico e o

\footnotetext{
Respectivamente: digital subscriber line, asymmetric digital subscriber line, cable TV.

2 O projeto é coordenado pelo Center for Research on Information Technology and Organizations (CRITO) da Universidade da California, Irvine.

3 As entrevistas foram realizadas pelo IDC, instituição de pesquisa especializada em tecnologias da informação, por encomenda do CRITO.
} 
acesso a informações on-line. Na medida que a Internet se transformou na principal tecnologia para o comércio eletrônico, substituindo o EDI na maioria das aplicaçôes, os termos Internet e comércio eletrônico são tratados aqui como sinônimos. Cabe esclarecer ainda que a unidade pesquisada é o estabelecimento entrevistado e não necessariamente a empresa como um todo.

Os resultados da pesquisa oferecem uma visão empírica abrangente e comparativa de como as empresas estão incorporando a Internet em suas atividades. Este artigo focaliza o caso brasileiro e aborda três temas particularmente relevantes para o estudo da difusão tecnológica. O primeiro tema envolve a importância relativa dos fatores globais e locais como determinantes da difusão do comércio eletrônico. Desde o pioneiro Future Shock de Alvin Tofler (1968), as tecnologias da informação e comunicação (TIC) vem sendo destacadas como instrumentos poderosos para a aceleração do processo de globalização do capitalismo. Tal argumento ganhou força com o advento da Internet comercial e pode ser ilustrado com a visão globalizante preconizada por Castells (1997):

A economia global irá se expandir no século XXI valendo-se do aumento de poder das telecomunicaçôes e do processamento das informaçôes. Ela penetrará todos os países, territórios e culturas, todos os fluxos de comunicações e redes financeiras, implacavelmente varrendo o planeta em busca de novas oportunidades de lucro.

No caso brasileiro, entretanto, a difusão da Internet pode não estar sujeita aos mesmos fatores determinantes observados em economias centrais. Questionando a visão globalizante, examinamos a hipótese de que no Brasil os fatores locais têm maior importância relativa como indutores da difusão. Empresas multinacionais efetivamente comandam redes produtivas de empresas que trabalham interconectadas por sistemas de informação e comunicação de alta qualidade e velocidade, exercendo um papel facilitador para a entrada de seus parceiros no comércio eletrônico. No entanto, poucas empresas brasileiras estão diretamente integradas com cadeias produtivas globais o que requer uma revisão dos fatores preponderantes da difusão do comércio eletrônico.

O segundo tema aborda uma questão particularmente relevante para o desenvolvimento das novas empresas virtuais. A literatura especializada (ver 
entre outros Kalakota \& Robinson, 1999; Shane \& Venkatraman, 2000) consideram as empresas que operam exclusivamente na Internet, a exemplo da Amazon, eBay, e Yahoo, como arautos de uma "nova economia", capazes de ameaçar a liderança das empresas tradicionais. A facilidade de comunicação e coordenação entre agentes econômicos proporcionada pela world wide web estaria criando novas formas de transações, reconfigurando mercados, revolucionando organizações e alterando modelos de negócios. Em conseqüência, estaríamos vivendo um momento de ruptura com padrões de organização industrial preexistentes, favorecendo empresas estruturadas em torno das novas tecnologias.

Apesar de reconhecer a existência de "janelas de oportunidades" criadas pelo comércio eletrônico para a entrada de novas empresas do mercado, rompendo barreiras à entrada longamente estabelecidas, entendemos que o sucesso da introdução das novas tecnologias depende fortemente da experiência prévia e da capacitação tecnológica e organizacional adquirida por indivíduos e instituições em tecnologias da informação. Nossa segunda hipótese, formulada com base na literatura neo-schumpeteriana (ver Dosi et al., 1992), é que a difusão do comércio eletrônico depende fortemente da trajetória passada no uso das tecnologias da informação, assim como a inclinação de cada setor para a automação e da influência dos fatores locais. Assim, esperamos que passada a ação inicial dos inovadores, o comércio eletrônico passe a ser liderado pelas empresas tradicionais de cada setor.

O terceiro tema refere-se à importância do porte da empresa para o uso do comércio eletrônico. A literatura especializada destaca as oportunidades para micro e pequenas empresas na Internet, devido à redução de custos de transação e ao acesso facilitado aos mercados. Mais recentemente, entretanto, evidências têm sido apresentadas sobre o papel da escala de produção para a adoção do comércio eletrônico, o que favoreceria sua difusão em empresas de maior porte. Zhu et al. (2002), por exemplo, mostram que as economias de escala e escopo relacionadas aos investimentos em pessoal qualificado, software e sistemas de informação e comunicação são fatores determinantes da difusão de formas mais avançadas de comércio eletrônico. As economias de escala ocorrem quando o aumento da produção implica em redução nos custos marginais. Já as economias de escopo surgem na medida que as empresas diluem custos fixos 
por uma maior gama de produtos e serviços. Ambos os conceitos são relevantes para analisar a economia digital. A Internet favorece economias de escala porque permite que atividades com rendimentos decrescentes em escala sejam substituídos por atividades com economias de escala crescentes. Na medida que a informação é cara para produzir, mas muito barata de reproduzir, seus custos são dominados pelo investimento na primeira cópia (Shapiro \& Varian, 1999). Por exemplo, o lançamento de um site transacional na Internet pode requerer consideráveis investimentos em design, integração com sistemas organizacionais existentes e na segurança de dados. Entretanto, os custos para adicionar novos clientes são desprezíveis. As economias de escopo, por sua vez, produzem sinergias ao gerar diferentes produtos e serviços utilizando a mesma infra-estrutura. $\mathrm{O}$ comércio eletrônico oferece várias oportunidades para obtenção de economias de escopo porque permite o compartilhamento de redes, arquivos, equipamentos, conhecimento tecnológico e canais de distribuição. Na medida que a empresa desenvolve o comércio eletrônico, acaba por identificar novas oportunidades para usar sua infra-estrutura para entrar em novos negócios. Embora a economia da informação ofereça oportunidades para pequenas empresas, principalmente no acesso a informações e ao mercado, as maiores chances parecem estar reservadas a empresas de maior escala e escopo de operaçôes.

Nossa hipótese para o caso brasileiro é que o potencial de adoção depende não apenas do porte da empresa, mas principalmente da intensidade de informação de suas operações. Informação pode ser definida como tudo aquilo que pode ser digitalizável, ou seja, transformável em um fluxo de bits. Sua intensidade seria medida pela participação do custo das atividades de coleta, processamento, análise e transmissão da informação em relação aos custos totais da empresa. Esperamos que o comércio eletrônico tenha este viés porque a informação, ao contrário dos produtos físicos, pode facilmente ser digitalizada e transmitida.

\section{Determinantes da difusão do comércio eletrônico no contexto brasileiro}

Tecnologicamente, o Brasil é um país muito heterogêneo, combinando ilhas de excelência em aplicações avançadas de TI (Tecnologias de Informação) com a desconexão de amplos segmentos da economia e da sociedade. Como 
quinto país mais populoso do mundo e contando com uma renda per capita em torno da média mundial, o País apresenta massa crítica suficiente para a difusão do comércio eletrônico. As grandes empresas e aquelas que atuam em setores intensivos em informação são as que colhem maiores benefícios do comércio eletrônico. Já as empresas de pequeno e médio porte, sobretudo no setor industrial, estão atrasadas na incorporação de novas tecnologias. Do ponto de vista dos consumidores individuais, a heterogeneidade da difusão da Internet é ainda mais marcante. Na região metropolitana de São Paulo, por exemplo, exatamente um terço ${ }^{4}$ da população tem acesso a computadores, seja em casa ou no trabalho. Quando consideramos o acesso por classe de renda, verificamos que $62 \%$ dos indivíduos pertencentes às classes A e B têm acesso a computadores, contra $22 \%$ dos indivíduos da classe $\mathrm{C}$ e apenas $11 \%$ dos indivíduos das classes $\mathrm{D} / \mathrm{E}$. $\mathrm{O}$ acesso à Internet apresenta um perfil ainda mais concentrado: entre os indivíduos com acesso a computador nas classes A/B, 71\% acessam a Internet; já no caso dos pertencentes às classes $\mathrm{D} / \mathrm{E}$, essa proporção reduzia-se para 49\%. Além da má distribuição de renda, a baixa escolaridade da população e a precária infra-estrutura informacional das periferias contribuem para a exclusão digital.

Dentre os fatores facilitadores da difusão, cabe destacar a melhoria da infra-estrutura de telecomunicações, a exemplo do que vem acontecendo em todo o mundo. Encorajados por inovaçóes tecnológicas, pela abertura do mercado brasileiro à concorrência, e pela histórica demanda reprimida por telefones no Brasil, as novas concessionárias investiram pesadamente no aumento da capacidade da rede. De 1998, quando o sistema de telecomunicações foi privatizado, ao ano 2000, os investimentos no setor atingiram uma média de $1,36 \%$ do PIB, um percentual muito superior à média histórica brasileira e latino-americana. Em 2001, os investimentos declinaram, mas ainda representaram $20 \%$ do investimento direto estrangeiro. Neste mesmo ano, 58,9\% dos domicílios brasileiros contavam com serviços telefônicos (7,8\% com celular apenas) contra 37,6\% em $1999 .{ }^{5}$ Entretanto, com o esgotamento da demanda reprimida, a expansão da rede foi interrompida a partir de 2002. A saturação dos usuários potenciais com poder aquisitivo para pagar pelos serviços pode ser

\footnotetext{
4 Pesquisa contratada junto ao IBOPE em maio de 2000.

5 Fonte: PNAD/IBGE, 2002. www.ibge.gov.br/pnad, 20 de setembro de 2002.
} 
percebida também na TV a cabo, que constitui alternativa para transmissão de Internet em banda larga, mas que atinge hoje a menos de 8\% dos domicílios brasileiros (ver Tabela 1).

TABELA 1

Evolução da Infra-estrutura de Telecomunicações no Brasil

\begin{tabular}{|c|c|c|c|c|c|c|c|c|}
\hline Infra-estrutura de Telecomunicações & 1995 & 1996 & 1997 & 1998 & 1999 & 2000 & 2001 & 2002 \\
\hline Investimentos telecom (\% do PIB) & 0,63 & 0,88 & 0,86 & 1,35 & 1,25 & 1,49 & & \\
\hline Linhas fixas por 1.000 hab. & 85,12 & 95,68 & 106,57 & 120,51 & 148,73 & 181,8 & 216,9 & $280^{*}$ \\
\hline Celulares por 1.000 hab. & 8,25 & 15,82 & 28,46 & 46,79 & 89,49 & 136,31 & 166,6 & \\
\hline \% digitalização das linhas telefônicas & 46,7 & 57,13 & 67,8 & 73,16 & 84,59 & 92,5 & $97,2^{*}$ & \\
\hline \% residências com linha telefônica & & & & & & 37,6 & $58,9^{* *}$ & \\
\hline \% residências com TV a cabo* & & 4,7 & & 6,2 & 6,5 & 7,7 & 8,0 & 7,7 \\
\hline
\end{tabular}

Fonte: ITU Yearbook of Statistics, 2000; ITU, 2002.

*Fonte: ANATEL: www.anatel.gov.br

** Fonte: PNAD (IBGE, 2001).

O desenvolvimento da infra-estrutura de Internet segue, com um certo hiato, uma trajetória de difusão similar à apresentada pelos serviços de telecomunicações. Apesar de continuar crescendo, deverá logo atingir um teto em função do baixo poder aquisitivo da maioria da população. A última PNAD (Pesquisa Nacional por Amostra de Domicílios, IBGE, 2001) mostrou que os microcomputadores estão presentes em 12,6\% dos domicílios brasileiros, dos quais 8,6\% com acesso à Internet (ver Tabela 2). Outra importante infra-estrutura para a difusão do comércio eletrônico é número de hosts (servidores com acesso à Internet) por habitantes, que no Brasil tem dobrado a cada ano. As firmas pesquisadas no projeto do CRITO no Brasil investem em média 4,5\% de seu faturamento em TI, contra 8\% nos Estados Unidos, 5\% na Europa e 3\% na América Latina. 
TABELA 2

Evolução da Internet, Tl e Comércio Eletrônico no Brasil

\begin{tabular}{|c|c|c|c|c|c|c|c|}
\hline Infra-estrutura de Internet e TI & 1995 & 1996 & 1997 & 1998 & 1999 & 2000 & 2001 \\
\hline Internet hosts por 1.000 hab. & 0,13 & 0,49 & 0,73 & 1,3 & 2,66 & 5,15 & 9,53 \\
\hline Usuários de Internet por 1.000 hab. & 1,09 & 4,69 & 8,19 & 15,07 & 20,83 & 29,39 & 46,36 \\
\hline$\%$ Domicílios com acesso à Internet $^{A}$ & & & & & & & 8,6 \\
\hline Custo acesso à Internet, 20 hrs, US\$ & & & & & & & 5,95 \\
\hline Custo acesso à Internet, ilimitado & & & & & & & 7,81 \\
\hline Gastos em TI como \% do PIB & 0,98 & 1,15 & 1,47 & 1,61 & 2,21 & 2,38 & \\
\hline PCs por 1.000 hab. & 17,33 & 21,54 & 26,27 & 30,15 & 36,31 & 44,09 & 62,6 \\
\hline$\%$ Domicílios com $\mathrm{PCs}^{\mathrm{B}}$ & & & & & & & 12,6 \\
\hline Produção de hardware US\$M & 6.500 & 7.700 & 8.150 & 8.320 & 8.569 & 9.083 & \\
\hline Exportações de hardware, US\$M & 186 & 205 & 257 & 249 & 321 & 1.100 & \\
\hline Taxa de pirataria de software (\%) & 0.74 & 0.68 & 0.62 & 0.61 & 0.58 & 0.58 & \\
\hline
\end{tabular}

Fontes: International Telecommunications Union (ITU), International Data Corporation (IDC), World Bank, Reed Electronics Research, Netcraft, BSA Piracy Study, International Labour Organization (ILO), OECD.

A PNAD/IBGE. Informação sobre PC e Internet foram coletadas pela PNAD a partir de 2001.

B FGVSP (2002).

Do ponto de vista setorial, no Brasil o setor bancário é historicamente líder na adoção de tecnologias da informação, sendo igualmente líder no uso da Internet em atividades de marketing, transaçóes, serviços e suporte on-line. Ao contrário de muitos outros países que limitam o escopo de atividades das instituiçôes financeiras, os bancos brasileiros atuam nas áreas comercial, investimentos, poupança e crédito imobiliário, seguros e bolsa de valores. Além disso, o governo utiliza extensivamente os bancos para arrecadação fiscal e transferência de recursos. Em função desta diversificada gama de atividades os grandes bancos brasileiros podem ser definidos como "supermercados de serviços". 
Um ambiente econômico estável é geralmente considerado como condição necessária para a difusão de novas tecnologias, pois incertezas sobre o comportamento futuro de variáveis econômicas, como preços relativos e crescimento do mercado, podem inibir as decisões de investimentos incorporando novas tecnologias. As tecnologias da informação parecem fugir a estas regras por serem ferramentas apropriadas para lidar com ambientes econômicos instáveis. Ao acelerar os fluxos de informações, as TI permitiram que os agentes econômicos capturassem benefícios das altas taxas de inflação prevalecentes no Brasil até meados da década de 1990. Os altos juros nominais ofereceram um incentivo, e não uma barreira, para a automação bancária, pois um fluxo eficiente de informações permitia aos bancos obter receitas extras com ofloating, aplicando no overnight os recursos financeiros em trânsito. Em conseqüência, os bancos brasileiros foram pioneiros na automação eletrônica, realizando investimentos e desenvolvendo capacitações que se revelaram cruciais para oferecer posteriormente serviços bancários on-line.

A política de informática adotada no Brasil na década de 1980, apesar de suas dificuldades em estimular a competitividade da indústria, representou um forte estímulo para a capacitação tecnológica local, induzindo a entrada de alguns dos maiores bancos brasileiros (Itaú, Bradesco e Banco do Brasil) na produção de hardware e software. Tais investimentos fortaleceram os elos existentes entre o processo de inovação e difusão. Cassiolato (1992) argumenta que os usuários de TI são particularmente importantes para o processo de inovação-difusão, na medida que o software é flexível de forma a permitir o desenvolvimento de aplicações apropriadas a cada tipo de negócio. Tal flexibilidade permite que usuários incorporem conhecimentos específicos de seu processo em sistemas de TI (Aksoy, 1990). Os problemas técnicos que surgem durante o processo de inovação-difusão requerem estreita cooperação entre fornecedores e usuários, favorecendo a competitividade de ambos agentes.

\section{Análise dos resultados da pesquisa}

\section{Globalização}

O papel das forças globais na difusão do comércio eletrônico tem sido amplamente debatido na literatura, que destaca o fato do comércio internacional e das redes internacionais de negócios serem importantes impulsionadores da troca 
on-line de informações. Analisando o caso de países em desenvolvimento, O'Connor (2002:57) sugere que os setores pioneiros no uso do comércio eletrônico seriam aqueles mais expostos à competição internacional. Já para Gereffi (2002:20), as influências seriam mútuas, pois o comércio eletrônico também contribuiria para a integração funcional de atividades dispersas internacionalmente:

"the new digital era of globalization is characterized by a dramatic increase in connectivity that is melting the information glue that holds corporations and global value chains together."

No caso brasileiro, entretanto, a globalização parece não exercer um papel comparável aos outros países incluídos na pesquisa como agente da difusão do comércio eletrônico. Apesar da abertura ocorrida na década de 1990 para investimentos e comércio exterior, e de manter fortes vínculos tecnológicos internacionais, a economia brasileira está relativamente mais orientada para o mercado interno. Poucas empresas locais são exportadoras e mesmo as subsidiárias de corporações multinacionais dependem menos do comércio internacional do que outras filiais em todo o mundo. Este fato se deve, em parte, às dimensões continentais do país que ocupa $6,4 \%$ do território e $2,8 \%$ da população mundial. As transações com o exterior representaram 19,1\% do PIB em 2000, um percentual comparável aos Estados Unidos (20,7\%).

A pesquisa realizada pelo CRITO confirma a esperada orientação para o mercado interno das empresas brasileiras. Apenas 4\% das empresas entrevistadas contavam com estabelecimentos no exterior, contra $23,9 \%$ da amostra internacional (ver Tabela 3). As operações de exportação e importação tampouco são tão importantes no Brasil quanto nos demais países estudados. As vendas no exterior representam em média 3,7\% da amostra brasileira, contra $12,1 \%$ da amostra global, enquanto que nas compras no exterior a relação é de $9,8 \%$ contra $20,3 \%$ respectivamente. A pesquisa mostra também que empresas brasileiras se sentem menos ameaçadas pela competição oriunda do exterior do que suas contrapartes na amostra global. Há, entretanto, diferenças marcantes entre grandes e pequenas empresas no tocante à internacionalização. As grandes empresas no Brasil são mais orientadas para o exterior do que as pequenas e médias, em todos os indicadores pesquisados. 
A amostra brasileira mostra que apesar da indústria manufatureira ser o setor mais globalizado da economia, tanto em termos de exportaçôes $(9,3 \%)$ quanto de importações $(10,4 \%)$, é paradoxalmente o menos intensivo em comércio eletrônico. Os bancos, por sua vez, contam com mais capital estrangeiro e investem relativamente mais no exterior, mas suas operaçôes são essencialmente voltadas para o mercado interno. O reduzido grau de globalização das empresas brasileiras sugere que fatores locais são mais importantes que os globais na determinação da adoção do comércio eletrônico.

TABELA 3

Indicadores de Globalização, 2002

\begin{tabular}{|c|c|c|c|c|c|c|c|}
\hline & \multicolumn{2}{|c|}{$\begin{array}{l}\text { Tamanho do } \\
\text { estabelecimento }\end{array}$} & \multicolumn{3}{|c|}{ Setor ${ }^{B}$} & \multicolumn{2}{|c|}{ Total } \\
\hline & PME $^{A}$ & Grande & Indústria & Distribuição & Finanças & Brasil $^{C}$ & Global $^{\mathrm{D}}$ \\
\hline \multicolumn{8}{|l|}{ Percentual de empresas com } \\
\hline estabelecimento no exterior & 3,5 & 22,9 & 2,5 & 4,3 & 11,4 & 4,0 & 23,9 \\
\hline \multicolumn{8}{|l|}{ Percentual de empresas com } \\
\hline matriz no exterior & 3,2 & 10,5 & 0,9 & 4,2 & 6,2 & 3,4 & 8,5 \\
\hline Média percentual de exportações & 3,3 & 17,9 & 9,3 & 1,8 & 3,7 & 3,7 & 12,1 \\
\hline Média percentual de importações & 9,7 & 15,2 & 10,4 & 9,8 & 5,3 & 9,8 & 20,3 \\
\hline \multirow{2}{*}{\multicolumn{8}{|c|}{$\begin{array}{l}\text { Impacto de competidores no } \\
\text { exterior } E\end{array}$}} \\
\hline & & & & & & & \\
\hline Baixo & 89,4 & 61,5 & 75,9 & 95,1 & 74,5 & 88,7 & 68,3 \\
\hline Moderado & 3,8 & 13,1 & 11,5 & 0,2 & 12,0 & 4,0 & 15,7 \\
\hline Alto & 6,8 & 25,3 & 12,6 & 4,6 & 13,6 & 7,3 & 15,2 \\
\hline
\end{tabular}

A PME (pequenos e médios estabelecimentos) contam com 25 a 250 empregados; grandes são aqueles com mais de 250 empregados.

B Indústria manufatureira inclui todos os estabelecimentos classificados como SIC 20-39; distribuição inclui atacado e varejo (SIC 50-54, 56-57, 59); finanças inclui bancos e seguradoras (SIC 60-65).

C Respostas foram ponderadas com base no número total de estabelecimentos, classificados por tamanho e setor para cada país estudado. A amostra no Brasil incluiu 68 estabelecimentos na inústria manufatureira, 68 na distribuição e 64 em bancos e seguros; no corte por tamanho, 98 estabelecimentos foram classificados como PME e 102 como grande.

D A pesquisa inclui amostras ponderadas de dez países combinados: Estados Unidos, México, Brasil, Alemanha, França, Dinamarca, Singapura, Taiwan, China e Japão. A amostra global por setor de atividade inclui 743 na manufatura, 701 na distribuição, e 695 em bancos e seguros; por tamanho 1.088 estabelecimentos foram classificados como PME e 1.053 como grandes.

E Percentagem baseada na amostra total.

Fonte: CRITO Global E-Commerce Survey, 2002. 


\section{Tecnologias adotadas por empresas brasileiras}

As comparaçôes internacionais (ver Tabela 4) mostram que as empresas brasileiras se situam acima da média global no uso de e-mail, Extranet, transferência eletrônica de fundos (TEF) e call centers, mas estão abaixo da média na disponibilidade de website, Intranet e EDI. Entre as empresas brasileiras, grandes estabelecimentos apresentam um maior uso de todas as tecnologias, equivalente em alguns casos ao dobro do uso em pequenos estabelecimentos. O setor financeiro lidera o uso de websites, Intranet e Extranet, mas fica atrás em EDI, TEF e uso de call centers. Tais dados sugerem que o tamanho da firma é mais importante que o setor como determinante da adoção. Indica também que os diferentes setores selecionam as tecnologias de forma a atender suas necessidades específicas de comunicação e comércio eletrônico.

TABELA 4

Uso de Tecnologia de Comércio Eletrônico, 2002

\begin{tabular}{|c|c|c|c|c|c|c|c|}
\hline \multirow[b]{2}{*}{ Percentual de empresas que usam: } & \multicolumn{2}{|c|}{$\begin{array}{l}\text { Tamanho do } \\
\text { estabelecimento }\end{array}$} & \multicolumn{3}{|c|}{ Setor ${ }^{B}$} & \multicolumn{2}{|c|}{ Total } \\
\hline & PME & Grande & Indústria & Distribuição & Finanças & Brasil $^{C}$ & Global $^{\mathrm{D}}$ \\
\hline E-mail & 100,0 & 99,9 & 100,0 & 100,0 & 99,9 & 100,0 & 98,5 \\
\hline Website & 70,4 & 80,8 & 77,7 & 67,1 & 84,5 & 70,7 & 74,1 \\
\hline Intranet & 36,8 & 71,7 & 45,2 & 34,0 & 50,1 & 37,7 & 63,6 \\
\hline Extranet & 32,9 & 44,6 & 41,4 & 29,2 & 46,4 & 33,2 & 32,7 \\
\hline \multicolumn{8}{|l|}{ - Acessível por fornecedores } \\
\hline e parceiros de negócios ${ }^{E}$ & 10,1 & 33,7 & 22,3 & 4,8 & 35,6 & 10,7 & 20,9 \\
\hline - Acessível por clientes ${ }^{\mathrm{E}}$ & 15,5 & 28,6 & 21,8 & 12,5 & 35,1 & 15,9 & 17,8 \\
\hline EDI & 35,7 & 71,9 & 38,9 & 35,8 & 35,1 & 36,7 & 44,3 \\
\hline - Utilizando apenas redes privadas $E$ & 7,0 & 25,8 & 4,2 & 9,2 & 2,7 & 7,5 & 19,4 \\
\hline — Utilizando apenas Internet ${ }^{\mathrm{E}}$ & 6,9 & 10,4 & 11,6 & 4,6 & 15,6 & 7,0 & 8,4 \\
\hline - ambos ${ }^{\mathrm{E}}$ & 21,8 & 35,7 & 23,1 & 22,0 & 16,8 & 22,2 & 15,9 \\
\hline TEF & 52,0 & 66,5 & 45,5 & 54,8 & 51,8 & 52,4 & 43,4 \\
\hline Call center & 45,6 & 62,5 & 46,8 & 46,3 & 35,1 & 46,1 & 32,3 \\
\hline
\end{tabular}

Notas A-E: ver Tabela 3.

Fonte: CRITO Global E-Commerce Survey, 2002. 
A adoção do comércio eletrônico também pode ser medida pelo grau de integração das aplicaçooes de Internet com sistemas de informações internos à empresa e externamente com seus fornecedores e clientes. A Tabela 5 mostra que há um percentual maior de empresas no Brasil muito integradas com bancos de dados e sistemas internos $(29,6 \%)$ do que a média global $(23,9 \%)$. Por outro lado, a média de empresas muito integradas a fornecedores e clientes no Brasil $(1,9 \%)$ se situa bem abaixo da média da amostra global (9,6\%). Podemos observar que empresas do setor financeiro apresentam um maior grau relativo de integração, tanto com sistemas internos de informação quanto com fornecedores e clientes. O setor de distribuição vem em segundo lugar, enquanto que o setor industrial apresenta o menor grau de integração. Tais resultados permitem duas hipóteses explicativas. A primeira está associada ao conceito de intensidade informacional: os setores de finanças e distribuição seriam mais intensivos em informações do que o setor industrial. A segunda hipótese explicativa seria o lento crescimento da indústria brasileira na última década (cerca de 1,5\% ao ano), fato que limitaria a capacidade de investimento do setor em novas tecnologias de gestão. Como esperado, as grandes empresas são mais integradas eletronicamente do que empresas de menor porte.

\section{Fatores determinantes do uso da Internet}

A Tabela 6 apresenta os fatores determinantes do uso do comércio eletrônico no Brasil segundo o porte e o setor de atividades do estabelecimento. Com relação ao porte, podemos observar que os grandes estabelecimentos enfrentam maior pressão de fontes externas à empresa do que as pequenas e médias para adotar o comércio eletrônico. Isso inclui não apenas as exigências de fornecedores e clientes, mas também o efeito demonstração de competidores on-line. Empresas de maior porte são também mais suscetíveis às oportunidades oferecidas pela Internet para reduzir custos e expandir mercados. Tais resultados confirmam amplamente nossa expectativa sobre a influência do tamanho da firma na adoção do comércio eletrônico. $O$ único aspecto no qual as pequenas empresas atribuem maior importância do que as grandes como fator determinante de adoção é relativo às compras governamentais pela Internet. A causa desta exceção é o fato das compras on-line realizadas pelo governo federal, através do site Comprasnet, darem preferência às pequenas empresas. 
TABELA 5

Estratégia de Integração das Empresas, 2002

\begin{tabular}{|c|c|c|c|c|c|c|c|}
\hline \multirow[b]{2}{*}{$\begin{array}{l}\text { Grau de integração das } \\
\text { aplicações da Internet com: }\end{array}$} & \multicolumn{2}{|c|}{$\begin{array}{l}\text { Tamanho do } \\
\text { estabelecimento }\end{array}$} & \multirow[b]{2}{*}{ Indústria } & \multirow{2}{*}{$\begin{array}{c}\text { Setor }^{B} \\
\text { Distribuição }\end{array}$} & \multirow[b]{2}{*}{ Finanças } & \multicolumn{2}{|c|}{ Total } \\
\hline & PME & Grande & & & & Brasil $^{C}$ & Global \\
\hline \multicolumn{8}{|l|}{$\begin{array}{l}\text { Bancos de dados e sistemas } \\
\text { de informação internos à empresa }\end{array}$} \\
\hline \% pouca ou nenhuma integração & 58,9 & 42,0 & 83,6 & 47,2 & 31,2 & 58,4 & 52,5 \\
\hline \% alguma integração & 12,0 & 10,3 & 0,7 & 17,2 & 18,8 & 12,0 & 23,6 \\
\hline \% muita integração & 29,1 & 47,7 & 15,6 & 35,6 & 50,1 & 29,6 & 23,9 \\
\hline \multicolumn{8}{|l|}{$\begin{array}{l}\text { Sistemas operados for fornecedores } \\
\text { e clientes } F\end{array}$} \\
\hline \% pouca ou nenhuma integração & 90,0 & 70,2 & 95,8 & 87,3 & 70,4 & 89,4 & 72,1 \\
\hline \% alguma integração & 8,5 & 16,1 & 1,8 & 12,0 & 11,2 & 8,7 & 18,3 \\
\hline \% muita integração & 1,6 & 13,7 & 2,5 & 0,7 & 18,4 & 1,9 & 9,6 \\
\hline
\end{tabular}

Notas A-D: ver Tabela 3.

E Pergunta: Usando uma escala de 5 pontos na qual 5 é "muita" e 1 é "nenhuma", atribua uma nota ao grau de integração eletrônica de suas aplicações de Internet com bancos de dados e sistemas de informação internos à empresa. Os graus 1 e 2 foram classificados como "pouca ou nenhuma integração"; grau 3 como "alguma" e graus 4 e 5 como "muita integração".

F Pergunta: Usando uma escala de 5 pontos na qual 5 é "muita" e 1 é "nenhuma", atribua uma nota ao grau de integração eletrônica de seus bancos de dados e sistemas de informação com aqueles operados por clientes e fornecedores. Graus 1 e 2 foram classificados como "pouca ou nenhuma integração"; grau 3 como "alguma" e graus 4 e 5 como "muita integração".

Fonte: CRITO Global E-Commerce Survey, 2002

A análise dos fatores determinantes da difusão revela diferenças setoriais significativas. As empresas financeiras são geralmente movidas pelo desejo de expandir mercados $(91,2 \%)$, seguidos pela necessidade de melhorar a coordenação com fornecedores e clientes $(67,8 \%)$. A Internet bancária já é uma prática bastante difundida no Brasil e constitui uma ferramenta essencial para conquistar novos clientes.

As motivações das empresas comerciais, tanto atacadistas como varejistas, para adotar o comércio eletrônico são distintas dos bancos. Como intermediários entre produtores e consumidores, elas estão essencialmente interessadas na coordenação logística com fornecedores e clientes (62,6\%). As empresas 
comerciais são também muito mais sensíveis às sinalizações do governo federal para compras on-line do que os demais setores analisados.

Já na indústria manufatureira, o comércio eletrônico é empurrado pelas perspectivas de redução de custos $(66,5 \%)$. A gestão on-line da cadeia produtiva constitui uma poderosa ferramenta competitiva, permitindo a redução de estoques e a aceleração dos ciclos de produção. A difusão do comércio eletrônico na indústria manufatureira é também resultado da exigência de grandes clientes, principalmente de distribuidores que comandam cadeias "puxadas pela demanda" ou de empresas industriais que encabeçam cadeias hierarquizadas de fornecedores de componentes e sistemas.

Um último aspecto importante sobre os determinantes da difusão é que as empresas brasileiras parecem perceber maiores oportunidades na Internet do que a média global. Com apenas uma exceção (principais competidores estão on-line), elas atribuem maior importância aos fatores determinantes sugeridos do que suas contrapartes no exterior. Tal observação é consistente com a hipótese proposta por Zhu et al. (2002:346) de que as empresas sediadas em países mais intensivos em TI são mais cautelosas na adoção de comércio eletrônico. Esta aparente contradição pode ser interpretada como fruto da experiência, muitas vezes negativa, de empresas de países avançados com a Internet, o que as levariam a relativizar o potencial da nova tecnologia.

\section{Barreiras e dificuldades}

A integração da Internet no mundo dos negócios requer profundas mudanças ao nível individual, organizacional, sistêmico e regulatório. Capacitar indivíduos e alterar hierarquias e rotinas organizacionais são tarefas muito mais complexas do que a simples introdução de novo software e hardware. Já as mudanças sistêmicas são inerentes à necessidade dos fornecedores e clientes acompanharem as mudanças requeridas para o uso do comércio eletrônico. Por fim, as mudanças regulatórias se referem à necessidade de nova legislação, de um regime fiscal compatível com as novas práticas de distribuição e de proteção legal aos negócios via Internet, visando garantir a privacidade, a defesa contra fraudes e comportamentos oportunistas. As dificuldades e os custos de promover tais mudanças constituem barreiras à difusão do comércio eletrônico. 
TABELA 6

Determinantes do uso da Internet

\begin{tabular}{|c|c|c|c|c|c|c|c|}
\hline \multirow[b]{2}{*}{$\begin{array}{l}\text { \% de empresas indicando a } \\
\text { importância do fator como } \\
\text { determinante da adoção }\end{array}$} & \multicolumn{2}{|c|}{$\begin{array}{l}\text { Tamanho do } \\
\text { estabelecimento }\end{array}$} & \multirow[b]{2}{*}{ Indústria } & \multirow{2}{*}{$\begin{array}{l}\text { Setor }^{\text {B }} \\
\text { Distribuição }\end{array}$} & \multirow[b]{2}{*}{ Finanças } & \multicolumn{2}{|c|}{ Total } \\
\hline & PME & Grande & & & & Brasil $^{\mathrm{C}}$ & Global $^{\mathrm{D}}$ \\
\hline Demanda dos clientes & 44,4 & 56,3 & 28,5 & 50,4 & 67,8 & 44,7 & 36,9 \\
\hline Principais competidores estão on-line & 26,3 & 48,8 & 7,5 & 34,8 & 38,5 & 26,9 & 31,3 \\
\hline Demanda dos fornecedores & 23,7 & 45,1 & 7,2 & 30,8 & 41,9 & 24,3 & 22,3 \\
\hline Redução de custos & 60,5 & 71,6 & 66,5 & 58,3 & 63,7 & 60,8 & 35,7 \\
\hline $\begin{array}{l}\text { Expandir o mercado para produtos } \\
\text { e serviços existentes }\end{array}$ & 59,1 & 67,5 & 47,6 & 62,7 & 91,2 & 59,3 & 47,9 \\
\hline $\begin{array}{l}\text { Entrar em novos negócios } \\
\text { ou mercados }\end{array}$ & 53,8 & 64,1 & 36,4 & 61,8 & 67,1 & 54,1 & 42,0 \\
\hline $\begin{array}{l}\text { Melhorar coordenação com } \\
\text { fornecedores e clientes }\end{array}$ & 60,8 & 66,6 & 56,1 & 62,6 & 67,8 & 60,9 & 43,7 \\
\hline Exigência das compras governamentais & 25,6 & 18,5 & 2,9 & 35,8 & 20,4 & 25,4 & 15,2 \\
\hline Incentivos do governo & 14,3 & 21,5 & 4,3 & 18,3 & 31,2 & 14,5 & 8,3 \\
\hline
\end{tabular}

Notas A-D: ver Tabela 3.

E Pergunta: Usando uma escala de 5 pontos na qual 5 é "muita" e 1 é "nenhuma", atribua uma nota à importância de cada fator como determinante da decisão de sua empresa utilizar a Internet para realizar negócios. Graus 4 e 5 foram classificados como "fatores determinantes significativos".

Fonte: CRITO Global E-Commerce Survey, 2002.

As evidências apresentadas na tabela a seguir nos ajudam a entender a natureza das barreiras enfrentadas por empresas de diferentes portes e setores para adotar o comércio eletrônico. No Brasil, os principais obstáculos são de ordem regulatória: falta de um regime jurídico próprio, incluindo a proteção à privacidade e à segurança dos dados (48,6\%); garantias insuficientes para as compras pela Internet $(41,4 \%)$; falta de regras legais para comércio eletrônico $(31,6 \%)$. Preocupações quanto à taxação dos negócios via Internet foram citadas por $26,8 \%$ das empresas brasileiras entrevistadas, comparadas a apenas $16,5 \%$ na amostra global. Tais resultados revelam que o papel do governo enquanto regulador do comércio eletrônico é mais importante do que supúnhamos 
inicialmente. Em artigo recente (Tigre \& Dedrick, 2002), argumentamos que os governos teriam um papel mais efetivo a cumprir como usuários e indutores de práticas de comércio eletrônico do que como meros reguladores. A pesquisa empírica não confirmou este argumento, pois mostra que, embora os governos possam desempenhar um papel positivo como promotores, especialmente para pequenas empresas, mais importante ainda seria exercer seu papel enquanto regulador no comércio eletrônico. Isso não quer dizer que o papel de promotor não seja relevante. Conforme mostrou a Tabela 6, mais de um quarto das empresas brasileiras consideram as compras on-line do governo como um fator determinante de sua entrada na Internet, um percentual maior do que revelado na amostra global $(15,2 \%)$. Incentivos fiscais para a compra de equipamentos de TI também exercem um papel positivo, principalmente para grandes empresas e para o setor financeiro. Entretanto, garantir proteção legal é uma necessidade considerada ainda mais premente.

$\mathrm{O}$ argumento de que pequenas empresas enfrentam maiores dificuldades para implantar o comércio eletrônico não são plenamente confirmados pelos resultados da pesquisa sobre as barreiras à difusão. As grandes empresas atribuem maior importância relativa às dificuldades em garantir privacidade $\mathrm{e}$ segurança $(55,1 \%)$, à necessidade de promover mudanças organizacionais $(41,1 \%)$, aos altos custos de implementação de sites para comércio eletrônico (39,3\%) e em termos de difusão de cartão de crédito no País $(33,8 \%)$. Já as pequenas e médias empresas consideram como obstáculo relativamente maior a falta de um aparato regulatório, os custos de acesso à Internet e ao fato de seus clientes não usarem a tecnologia. As preocupações refletem recursos e universos competitivos distintos e são, a nosso ver, inconclusivas quanto ao papel do porte para a difusão da Internet.

A análise setorial das barreiras mostra que o setor de distribuição enfrenta maiores dificuldades do que os demais. A preocupação com segurança $(61,1 \%)$ e com o fato dos clientes não usarem a tecnologias $(51,7 \%)$ pode ser explicada pela natureza pulverizada dos negócios B2C (business-to-commerce). As dificuldades de contratar pessoal qualificado em comércio eletrônico também afetam principalmente o setor de distribuição (41\%). Tradicionalmente este setor paga salários inferiores à indústria e ao setor financeiro e conseqüentemente podem enfrentar dificuldades em atrair pessoal qualificado. Podemos observar a existência de uma 
TABELA 7

Barreiras e Dificuldades para Adoção de Comércio Eletrônico

\begin{tabular}{|c|c|c|c|c|c|c|c|}
\hline \multirow[b]{2}{*}{$\begin{array}{l}\text { Percentual de empresas que } \\
\text { indicaram o fator abaixo como } \\
\text { obstáculo significativo E }\end{array}$} & \multicolumn{2}{|c|}{$\begin{array}{l}\text { Tamanho do } \\
\text { estabelecimento }\end{array}$} & \multirow[b]{2}{*}{ Indústria } & \multirow{2}{*}{$\begin{array}{l}\text { Setor }^{B} \\
\text { Distribuição }\end{array}$} & \multirow[b]{2}{*}{ Finanças } & \multicolumn{2}{|c|}{ Total } \\
\hline & PME & Grande & & & & Brasil C & Global $^{\mathrm{D}}$ \\
\hline $\begin{array}{l}\text { Necessidade de interação } \\
\text { pessoal com clientes }\end{array}$ & 32,6 & 30,2 & 26,0 & 34,7 & 40,0 & 32,5 & 33,8 \\
\hline $\begin{array}{l}\text { Preocupação com privacidade } \\
\text { e segurança }\end{array}$ & 48,4 & 55,1 & 17,1 & 61,1 & 46,4 & 48,6 & 44,2 \\
\hline Clientes não usam a tecnologia & 48,5 & 20,0 & 38,5 & 51,7 & 31,4 & 47,6 & 31,4 \\
\hline $\begin{array}{l}\text { Dificuldades de contratar pessoal } \\
\text { qualificado em comércio eletrônico }\end{array}$ & 34,3 & 32,2 & 16,7 & 41,0 & 29,8 & 34,2 & 26,5 \\
\hline $\begin{array}{l}\text { Nível de difusão de cartão de } \\
\text { crédito no País }\end{array}$ & 22,9 & 33,8 & 26,3 & 22,0 & 22,3 & 23,2 & 20,3 \\
\hline $\begin{array}{l}\text { Custos de implementação de } \\
\text { sites para comércio eletrônico }\end{array}$ & 33,4 & 39,3 & 18,0 & 39,0 & 35,6 & 33,6 & 33,6 \\
\hline $\begin{array}{l}\text { Necessidade de promover } \\
\text { mudanças organizacionais }\end{array}$ & 32,6 & 41,1 & 16,5 & 38,9 & 40,5 & 32,9 & 23,9 \\
\hline $\begin{array}{l}\text { Falta de habilidades para integrar a } \\
\text { Internet nas estratégias de negócios }\end{array}$ & 22,3 & 24,8 & 4,5 & 29,0 & 25,7 & 22,4 & 24,8 \\
\hline Custo do acesso à Internet & 20,7 & 8,9 & 1,4 & 28,7 & 11,2 & 20,4 & 15,1 \\
\hline Falta de legislação adequada & 31,9 & 22,2 & 26,1 & 34,3 & 22,2 & 31,6 & 24,2 \\
\hline Impostos sobre vendas on-line & 27,1 & 17,6 & 3,3 & 35,8 & 36,3 & 26,8 & 16,5 \\
\hline $\begin{array}{l}\text { Proteção legal inadequada para as } \\
\text { compras pela Internet }\end{array}$ & 41,6 & 34,4 & 36,2 & 43,2 & 46,9 & 41,4 & 34,1 \\
\hline
\end{tabular}

Notas A-D: ver Tabela 3.

E Pergunta: Usando uma escala de 5 pontos na qual 5 é "muita" e 1 é "nenhuma", atribua uma nota ao grau de significancia dos seguintes obstáculos ao uso commercial da Internet no seu estabelecimento. Graus 4 e 5 foram classificados como "obstáculos significativos".

Fonte: CRITO Global E-Commerce Survey, 2002.

correlação entre o padrão de uso relativamente menos avançado da Internet e a dificuldade de encontrar pessoal qualificado.

$\mathrm{Na}$ medida que o problema de encontrar pessoal com experiência em comércio eletrônico é maior no Brasil $(34,2 \%)$ do que na amostra global (26,5\%), precisamos olhar também o estado do nível educacional do País e a qualificação dos profissionais para absorver as novas tecnologias. O problema 
não parece residir no aspecto quantitativo, pois existiam no país mais de três milhões de estudantes universitários em 2002, um salto de $43 \%$ em relação a 1998 (INEP, 2003). A falta de pessoal qualificado parece estar associada à insuficiente experiência prática com TI, tanto na escola quanto nos postos de trabalho. Por outro lado, um indicador positivo é que a falta de habilidades para integrar a Internet nas estratégias de negócios é considerada um problema relativamente menor no Brasil $(22,4 \%)$ do que na amostra global $(24,8 \%)$, o que revela a disponibilidade de gerentes e técnicos de alto nível.

Com relação ao setor financeiro, suas maiores dificuldades residem na necessidade de interação pessoal com clientes (40\%), na necessidade de promover mudanças organizacionais $(40,5 \%)$ e na proteção legal inadequada para as transaçôes pela Internet $(46,9 \%)$. Tais dificuldades refletem a natureza dos negócios bancários, envolvendo transações financeiras com complexos dispositivos de segurança. O uso de cartão de crédito, responsável por cerca de $90 \%$ dos pagamentos on-line no comércio eletrônico B2B (business-to-business), não constitui um obstáculo relevante para as empresas. Conforme mostramos em Tigre e Dedrick (2002), os consumidores brasileiros são os maiores usuários de cartões de crédito na América Latina e ocupam a oitava posição no ranking mundial, com 30 milhôes de cartôes emitidos. Em 2000, as compras com cartão no Brasil somaram US\$ 26,5 bilhões, equivalentes a $7 \%$ do consumo doméstico privado total. $^{6}$

Com relação aos custos da Internet como barreira à difusão, as empresas brasileiras atribuem a mesma importância aos altos investimentos requeridos para implantação de sites que suas contrapartes em outros países (33,6\%). Já o custo de acesso à Internet é considerado um problema maior no Brasil (20,4\% contra $15,1 \%$ ), mas parece ser um problema restrito às pequenas e médias empresas.

\section{Difusão do comércio eletrônico}

O comércio eletrônico vem evoluindo rapidamente no Brasil, tendo crescido 20 vezes em apenas dois anos, pulando de US\$ 100 milhões para cerca de US\$ 2 bilhões. Em 2000, representava 0,32\% do PIB, sendo que o B2B respondia por $90 \%$ do comércio eletrônico total.

6 Fonte: Gazeta Mercantil Latino-Americana, 12-18 fev. 2001, p.26. 
TABELA 8

Formas de Uso da Internet, 2002

\begin{tabular}{|c|c|c|c|c|c|c|c|}
\hline \multirow[b]{2}{*}{$\begin{array}{l}\text { Percentual de empresas usando } \\
\text { a Internet para: }{ }^{E}\end{array}$} & \multicolumn{2}{|c|}{$\begin{array}{l}\text { Tamanho do } \\
\text { estabelecimento }\end{array}$} & \multicolumn{3}{|c|}{ Setor ${ }^{B}$} & \multicolumn{2}{|c|}{ Total } \\
\hline & PME & Grande & Indústria & Distribuição & Finanças & Brasil ${ }^{C}$ & Global $^{\mathrm{D}}$ \\
\hline Propaganda e marketing & 58,6 & 59,1 & 73,9 & 50,7 & 90,8 & 58,6 & 57,6 \\
\hline Realizar vendas on-line & 28,0 & 32,3 & 13,4 & 33,6 & 43,1 & 28,2 & 29,9 \\
\hline $\begin{array}{l}\text { Assistência técnica e suporte } \\
\text { pós-venda }\end{array}$ & 22,6 & 40,1 & 25,9 & 21,2 & 38,4 & 23,1 & 43,7 \\
\hline Realizar compras on-line & 54,7 & 63,4 & 56,7 & 54,1 & 55,7 & 54,9 & 46,8 \\
\hline $\begin{array}{l}\text { Trocar dados operacionais } \\
\text { com fornecedores }\end{array}$ & 51,6 & 62,4 & 64,6 & 46,7 & 50,1 & 51,9 & 48,1 \\
\hline $\begin{array}{l}\text { Trocar dados operacionais } \\
\text { com clientes }\end{array}$ & 49,0 & 56,5 & 57,2 & 45,9 & 49,2 & 49,2 & 50,7 \\
\hline $\begin{array}{l}\text { Integração de processos de } \\
\text { negócios com fornecedores e } \\
\text { outros parceiros de negócios }\end{array}$ & 48,8 & 48,1 & 54,5 & 46,4 & 50,7 & 48,8 & 33,9 \\
\hline
\end{tabular}

Notas A-D: ver Tabela 3.

E Pergunta: Sua empresa usa a Internet para...

Fonte: CRITO Global E-Commerce Survey, 2002.

A pesquisa é clara sobre a natureza do uso do comércio eletrônico nos diferentes setores e tipos de firmas. No Brasil, o setor financeiro lidera o uso da Internet em atividades de marketing, vendas on-line, serviços e suporte ao cliente. A indústria manufatureira, por sua vez, é líder na troca de dados com fornecedores, clientes e parceiros de negócios. $\mathrm{O}$ setor de distribuição não lidera nenhuma aplicação em particular, mas todos os três setores apresentam um nível similar de compras on-line. De um modo geral, o setor financeiro se destaca, mas as diferenças não são tão grandes quanto esperadas, dada a reputação do setor como usuário de tecnologias avançadas.

As grandes empresas são usuários mais intensivos em praticamente todas as aplicações. A principal aplicação no conjunto das empresas entrevistadas é propaganda e marketing seguido de compras on-line. Venda on-line é a aplicação menos desenvolvida, especialmente em pequenas empresas do setor industrial. 


\section{Impactos do comércio eletrônico}

Um dos fenômenos mais flagrantes no panorama econômico mundial dos últimos dez anos tem sido o rápido crescimento das redes de negócios. Apesar deste processo ter se iniciado antes da Internet estar disponível para uso comercial, o comércio eletrônico contribui fortemente para este fenômeno. A Tabela 9 mostra que mais de um terço das empresas entrevistadas no Brasil verificaram um aumento dos impactos de rede a partir do comércio eletrônico, tais como o aumento do número de fornecedores $(39,8 \%)$ e canais de distribuição $(35,2 \%)$. As evidências mostram que as grandes empresas são as que mais aumentaram o número de canais de distribuição a partir da Internet, sugerindo que elas podem obter economias de escala em seus investimentos em comércio eletrônico.

A Internet também expõe as empresas a uma maior pressão competitiva. No total, as empresas brasileiras são tão afetadas em termos de aumento no número de competidores e aumento da pressão competitiva por parte dos atuais competidores quanto as empresas entrevistadas na amostra global. Porém, as empresas de menor porte relataram maior aumento da competição a partir de sua entrada na Internet. Uma possível explicação é que a realização de negócios eletrônicos tenha exposto as pequenas empresas à competição além dos limites de seus mercados tradicionais.

Dentre os setores analisados, as empresas financeiras são as que tendem a aumentar mais o número de canais de distribuição e também são as que enfrentam maior aumento na competição. O setor de distribuição, tanto atacadista quanto varejista, sofre um aumento similar na pressão competitiva. Na medida que estes setores operam essencialmente no mercado interno, o aumento da pressão competitiva é mais local do que global. Curiosamente, o setor industrial que enfrenta maior competição internacional por trabalhar com produtos "tradables" reportou um aumento muito menor na pressão competitiva do que os demais setores. Este fato dá suporte à hipótese de que no Brasil o comércio eletrônico é um fenômeno mais local do que global.

As grandes empresas parecem estar obtendo maiores benefícios que as menores através do aumento da eficiência interna, ampliação da área de vendas, pela melhoria dos serviços aos clientes, coordenação com fornecedores e fortalecimento da posição competitiva. Por outro lado, as pequenas empresas pare- 
TABELA 9

Impactos dos Negócios On-Line na Estrutura da Indústria, 2002

\begin{tabular}{|c|c|c|c|c|c|c|c|}
\hline \multirow[b]{2}{*}{$\begin{array}{l}\text { Percentual de empresas } \\
\text { indicando: }{ }^{E}\end{array}$} & \multicolumn{2}{|c|}{$\begin{array}{l}\text { Tamanho do } \\
\text { estabelecimento }\end{array}$} & \multicolumn{3}{|c|}{ Setor ${ }^{B}$} & \multicolumn{2}{|c|}{ Total } \\
\hline & PME & Grande & Indústria & Distribuição & Finanças & Brasil ${ }^{C}$ & Global $^{\mathrm{D}}$ \\
\hline $\begin{array}{l}\text { Número de canais de } \\
\text { distribuiçãoo aumentaram }\end{array}$ & 34,8 & 48,5 & 26,6 & 37,7 & 56,6 & 35,2 & 40,2 \\
\hline $\begin{array}{l}\text { Número de fornecedores } \\
\text { aumentou }\end{array}$ & 39,7 & 40,5 & 36,6 & 41,2 & 36,9 & 39,8 & 29,9 \\
\hline $\begin{array}{l}\text { Número de competidores } \\
\text { aumentou }\end{array}$ & 28,0 & 16,8 & 13,2 & 32,9 & 46,4 & 27,7 & 27,9 \\
\hline $\begin{array}{l}\text { Intensidade da competição } \\
\text { aumentou }\end{array}$ & 37,9 & 29,8 & 13,2 & 47,6 & 51,5 & 37,7 & 41,5 \\
\hline
\end{tabular}

Notas A-D: ver Tabela 3.

E Pergunta: Indique se os fatores seguintes tiveram aumento, decréscimo ou permaneceram iguais desde que sua empresa iniciou o uso da Internet para realizar negócios.

Fonte: CRITO Global E-Commerce Survey, 2002.

cem atribuir maior importância à redução de custos e dos estoques via comércio eletrônico. Grandes e pequenas empresas tendem a ter uma percepção similar sobre os impactos do comércio eletrônico no aumento das vendas.

O setor financeiro é o que mais se beneficia com a melhoria da eficiência interna, aumento de vendas e ampliação das áreas de vendas. A indústria de transformação, em contraste, reconhece mais os benefícios de melhorar os serviços aos clientes e da coordenação com fornecedores e clientes. Tais diferenças são típicas da natureza de seus negócios. Enquanto os bancos e outras empresas financeiras usam a Internet predominantemente como uma ferramenta de marketing, a indústria manufatureira busca melhorar sua eficiência através do comércio eletrônico. Mas mesmo neste quesito, o setor financeiro encontra maior potencial na medida em que manipula basicamente informações e não produtos físicos.

Consistente com nossa hipótese de que no Brasil o comércio eletrônico é mais um fenômeno local do que global, menos de 13\% das empresas relataram aumento das vendas internacionais desde que introduziram venda on-line, con- 
TABELA 10

Impactos dos Negócios On-Line, 2002

\begin{tabular}{|c|c|c|c|c|c|c|c|}
\hline \multirow[b]{2}{*}{$\begin{array}{l}\text { Percentual indicando alto } \\
\text { impacto: }\end{array}$} & \multicolumn{2}{|c|}{$\begin{array}{l}\text { Tamanho do } \\
\text { estabelecimento }\end{array}$} & \multicolumn{3}{|c|}{ Setor ${ }^{B}$} & \multicolumn{2}{|c|}{ Total } \\
\hline & PME & Grande & Indústria & Distribuição & Finanças & Brasil $^{C}$ & Global $^{\mathrm{D}}$ \\
\hline $\begin{array}{l}\text { Maior eficiência nos processos } \\
\text { internos }\end{array}$ & 32,4 & 52,6 & 38,8 & 29,6 & 57,0 & 32,9 & 33,9 \\
\hline $\begin{array}{l}\text { Aumento da produtividade do } \\
\text { trabalho }\end{array}$ & 40,3 & 40,7 & 37,2 & 41,7 & 36,4 & 40,3 & 27,2 \\
\hline Aumento nas vendas & 26,4 & 31,0 & 15,2 & 30,2 & 41,1 & 26,5 & 20,5 \\
\hline Aumento na área de vendas & 27,4 & 40,8 & 5,8 & 36,2 & 39,4 & 27,8 & 31,4 \\
\hline Melhoria nos serviços aos clientes & 44,8 & 55,9 & 60,9 & 39,1 & 42,3 & 45,1 & 34,8 \\
\hline Aumento das vendas internacionais & 12,8 & 11,7 & 13,0 & 12,8 & 10,8 & 12,8 & 19,5 \\
\hline Redução dos custos de compras & 25,0 & 26,2 & 44,2 & 17,5 & 27,8 & 25,1 & 17,7 \\
\hline Redução nos custos de estoque & 28,2 & 20,0 & 23,1 & 30,2 & 21,2 & 27,9 & 14,0 \\
\hline $\begin{array}{l}\text { Melhoria da coordenação com } \\
\text { fornecedores }\end{array}$ & 34,2 & 42,5 & 59,1 & 25,2 & 32,0 & 34,4 & 29,8 \\
\hline Melhoria da posição competitiva & 23,5 & 39,7 & 28,0 & 22,0 & 33,7 & 24,0 & 29,8 \\
\hline
\end{tabular}

Notas A-D: ver Tabela 3.

E Pergunta: Usando uma escala de 5 pontos, na qual 5 é "muito" e 1 é "nada", atribua uma nota ao grau de impacto dos seguintes fatores no seu estabelecimento desde que passou a usar a Internet para realização de negócios. As notas 4 e 5 foram classificadas como "grande impacto".

Fonte: CRITO Global E-Commerce Survey, 2002.

tra cerca de $20 \%$ na média dos países analisados. Os números são muito similares para empresas grandes e pequenas e através dos três setores, mostrando que não há um segmento da economia brasileira com orientação predominantemente global. Cabe lembrar que a maior parte das exportaçóes brasileiras é de produtos primários que não foram incluídos na pesquisa por não serem tipicamente usuários intensivos de comércio eletrônico. 


\section{Conclusões}

O advento do uso comercial da Internet levantou muitas expectativas sobre o surgimento de uma "nova economia" liderada por empresas estruturadas a partir da nova tecnologia. Após o sucesso inicial de alguns pioneiros, podemos observar que a Internet está deixando de ser uma tecnologia isolada, utilizada principalmente por empresas inovadoras, para ser incorporada nos sistemas de informações de organizações tradicionais. A pesquisa mostra que o comércio eletrônico, inicialmente dominado por empresas virtuais que o utilizavam como canal único de vendas, vem se tornando um instrumento complementar de negócios, adotado pela maioria das empresas em todo o mundo. Em muitos casos, as empresas virtuais acabaram sendo absorvidas por empresas existentes e se convertendo em um canal alternativo de comunicação e transação, integrando e complementando os sistemas preexistentes. A sinergia entre as operaçôes físicas e virtuais vem se revelando extremamente importante, de forma que um canal não pode mais prescindir do outro. Tal constatação nos permite questionar mitos amplamente difundidos na literatura especializada sobre os fatores determinantes e os impactos da Internet sobre a economia e sociedade.

$\mathrm{O}$ primeiro mito refere-se à predominância dos fatores globais como determinantes da difusão. A análise do caso brasileiro mostra que o comércio eletrônico está fortemente ancorado em setores intensivos em informação que são pouco afetados por transaçôes internacionais. Fatores locais parecem exercer um papel influente devido à trajetória econômica típica do País e das políticas adotadas pelo governo que, combinadas, levaram o comércio eletrônico a privilegiar determinadas aplicações em detrimento de outras. As empresas brasileiras não são atores globais importantes e o uso da Internet não parece induzir um maior envolvimento das empresas usuárias com a economia global. Tal conclusão contradiz a noção popularizada na literatura especializada de que o comércio eletrônico induz as empresas à globalização, um argumento que incorpora uma boa dose de "determinismo tecnológico". A pesquisa mostra que a nova tecnologia é usada de forma a apoiar as estratégias empresariais existentes, reforçando trajetórias estabelecidas.

O segundo mito diz respeito ao surgimento de uma nova economia, liderada por empresas virtuais. Nossa hipótese é que a difusão do comércio 
eletrônico, apesar de constituir uma janela de oportunidade para novas empresas, depende fortemente da trajetória passada no uso das tecnologias da informação. Na medida em que a difusão do comércio eletrônico avança, é possível perceber que ele constitui essencialmente uma nova aplicação das tecnologias da informação e não uma tecnologia disruptiva capaz de alterar a estrutura da indústria e abalar lideranças estabelecidas. Em um primeiro momento, o surgimento de empresas virtuais parecia indicar que o comércio eletrônico eliminaria barreiras à entrada, levando muitos autores a prever uma ampla reconfiguração dos mercados. Porém, em pouco tempo as empresas líderes, sobretudo aquelas com maior experiência em TI, conseguiram incorporar a Internet ao seu arsenal tecnológico, aproveitando sua maior capacitação, infraestrutura e reputação junto aos consumidores.

No caso brasileiro, ao contrário da maioria dos países estudados no projeto Globalization and Electronic Commerce, onde a difusão do comércio eletrônico é liderada pelo setor industrial, o setor financeiro lidera a adoção e colhe os maiores benefícios, graças à experiência e à capacitação tecnológica adquirida nas últimas duas décadas no desenvolvimento de sistemas de automação bancária. $\mathrm{O}$ setor financeiro capitalizou sua experiência prévia em TI para adotar amplamente o comércio eletrônico e integrá-lo aos sistemas de informação preexistentes. As grandes empresas dos setores de indústria e distribuição seguem a mesma trajetória, sendo inclusive mais avançadas que os bancos em determinadas aplicações da Internet. Por outro lado, empresas com pouca experiência em sistemas informatizados tradicionais encontram maiores dificuldades em incorporar e obter resultados do comércio eletrônico. Tais conclusóes dão apoio ao argumento neo-schumpeteriano de que a empresa evolui em um sentido determinado pelas competências acumuladas e pela natureza de seus ativos específicos. Apesar da Internet abrir oportunidades de mudança de trajetória, a "história conta", pois a empresa só se transforma tendo como base os conhecimentos adquiridos anteriormente.

O terceiro mito seria de que a Internet permitiria a superação das barreiras à entrada associadas à falta de economias de escala para competirem com empresas de maior porte. Tais oportunidades existiram efetivamente nos anos iniciais da Internet comercial, mas vem sendo progressivamente reduzidas na medida em que avança o processo de difusão. A pesquisa mostra que as grandes 
empresas são hoje claramente mais ativas na implementação e usam mais extensivamente o comércio eletrônico na maioria das aplicaçôes. Tal resultado é consistente com a noção de que a habilidade para obter economias de escala e de escopo constitui estímulo importante para a adoção. Também é consistente com a noção de que as grandes empresas contam com maior disponibilidade de recursos humanos e financeiros para investirem em comércio eletrônico.

Por outro lado, a pesquisa revelou alguns aspectos onde as grandes empresas enfrentam barreiras relativamente maiores do que as pequenas e médias. Por exemplo, elas enfrentam maiores obstáculos para realizar mudanças organizacionais do que as de pequeno porte, mostrando que a inflexibilidade organizacional é uma barreira que nega algumas das vantagens usufruídas pelas grandes empresas. Entretanto, a pesquisa parece indicar que, uma vez superado os obstáculos iniciais, os benefícios são potencialmente maiores nas grandes empresas. As empresas deste porte são as que mais usufruem do aumento da eficiência interna, aumento de vendas e melhores serviços aos clientes. As pequenas empresas obtêm benefícios tão grandes ou maiores em outras variáveis, mas as grandes empresas são as que mais reportaram aumento na competitividade (40\% contra 25\%), indicando que existem vantagens na diluição dos investimentos em comércio eletrônico sobre uma maior escala e escopo de atividades.

A intensidade informacional também parece cumprir um papel importante na adoção do comércio eletrônico. Empresas de um mesmo setor e de porte relativamente similar podem apresentar estágios assimétricos de difusão, segundo sua necessidade de troca de informaçôes. Os bancos varejistas, por exemplo, utilizam amplamente o Internet banking, na medida que suas operações envolvem a troca diária de informações com milhares de pequenos clientes. Já os bancos de investimento, considerados atacadistas por realizarem poucas transações com grandes clientes, são usuários pouco expressivos de comércio eletrônico. Operações de alto valor unitário justificam o contato pessoal, reduzindo a importância do uso da Internet, mesmo que o tamanho do estabelecimento, medido em termos de movimento financeiro, seja similar aos estabelecimentos varejistas.

Em síntese, além do setor e do porte da empresa, a intensidade informacional parece cumprir um papel determinante na difusão da Internet. Tais fatores, associados ao ambiente econômico e as políticas do governo, con- 
ferem a cada país uma trajetória única de difusão. As tendências “universais" são vetores importantes no desenvolvimento tecnológico, na criação de modelos de negócios e na sinalização de uma regulação internacional. Entretanto, não podemos prescindir do filtro dos fatores locais para entender os determinantes e os impactos da difusão do comércio eletrônico.

\section{References}

Aksoy, A., Innovation and diffusion dynamics of the information technology paradigm. Working Paper n.11. Center for Information and Technology, in SPRU, Brighton: University of Sussex, 1990.

ANATEL. Agência Nacional de Telecomunicações. Brasília www.anatel.gov.br

Cassiolato, J. The Role of User-Producer Relations in Innovation and Diffusion of New Technologies: Lessons from Brazil. D.Phil Thesis, University of Sussex, 1992.

Dosi, G.; Teece, D.; Winter, S., "Towards a Theory of Corporate Change: Preliminary Remarks”, in Dosi, G.; Giannetti, R.; Toninelli, P. (orgs.), Technology Enterprise in a Historical Perspective. Oxford: Claredon Press Oxford, 1992.

Fariselli, P., "E-Commerce for Development: A General Framework", in Goldstein, A.; O'Connor, D., Electronic Commerce for Development. Paris: OECD Development Centre, 2002.

Gereffi, G., "The Evolution of Global Value Chains in the Internet Era”, in Goldstein, A.; O'Connor, D., Eletronic Commerce for Development, OECD Development Centre, Paris, 2002.

FGVSP — Fundação Getulio Vargas de São Paulo (2002). Tecnologias da Informação: Cenários e Tendências. 13 Pesquisa Anual. Panorama do uso nas empresas. Available in www.fgvsp.br/ academico/estudos/cia/index. 9 out. 2002.

IBGE - Instituto Brasileiro de Geografia e Estatística . Pesquisa Nacional de Amostra por Domicílio (PNAD) 2001. www.ibge.gov.br/pnad

INEP — Sistema de Avaliação do Ensino Superior. Censo 2000. Ministério da Educação. www.inep.gov.br/imprensa/noticias/censo. 14 fev. 2003. 
ITU - International Telecommunications Union. Challenges to the Network — Internet for Development. Genebra, fev. 1999.

Telecommunication Union. International Telecommunication Union, Yearbook of Statistics 19912000, Genebra, 2001.

Kalakota, R.; Robinson, M., E-Business Roadmap for Sucess. Addison-Wesley, 1999.

O'Connor, D., "E-Commerce for Development: Between Scylla and Charybdis", in Goldstein, A.; O'Connor, D., Eletronic Commerce for Development, Paris: OECD Development Centre, 2002 .

OECD. E-Commerce: Impacts and Policy Changes. Economic Department Working Paper No. 252. OECD Paris, 2000.

Perez, C., The Present Wave of Technology Change. Implications for Competitive and Institutional Reform in Developing Countries. Paper prepared for the World Bank, 1988.

Shane, S.; Venkatraman, S., "The promise of entrepreunership as a field of research", in Academy of Management Review, 25, p.217-226, 2000.

Shapiro, C.; Varian, H., A Economia da Informação: como os princípios econômicos se aplicam a era da Internet. Rio de Janeiro: Editora Campus, 1999.

Simon, L. D., NetPolicy.Com. Public Agenda for a Digital World, Washington DC: Woodrow Wilson Center Press, 2000.

Tigre, P.; Dedrick, J. Globalization and Electronic Commerce: Environment and Policy in Brazil. CRITO, UCI, 2002.

et al. "Institutional Change and Technology: Impacts of Deregulation on the National Innovation System”, in Bauman, R., Brazil in the 1990s: An Economy in Transition. Londres: Palgrave, 2002.

Tofler, A., Future Shock. Londres: Collins, 1968.

Zhu, K; Kraemer, K; Xu, S. A cross-country study of electronic business adoption using the technology organization environment framework. ICIS 2002 Conference. Available at www.crito.uci/ publications, 2002. 